\title{
STRATEGIC AND FOCUSED SOLUTIONS TO CHALLENGES FACED \\ BY MEDICAL POSTGRADUATE STUDENTS IN PERFORMING \\ RESEARCH AT A SOUTH AFRICAN UNIVERSITY
}

\author{
M. E. Kisansa
}

Department of Diagnostic Radiology and Imaging

Sefako Makgatho Health Sciences University

Pretoria, South Africa

e-mail: megwaiswa@gmail.com / https://orcid.org/0000-0002-9148-7672

\section{H. Lubinga}

Markets and Economic Research Centre (MERC)

National Agricultural Marketing Council

Pretoria, South Africa

e-mail: moseslubinga@yahoo.co.uk / https://orcid.org/0000-0002-6608-8776

\section{ABSTRACT}

Background and objectives: Poor research output is a major issue at some South African Universities especially among medical postgraduate students. A number of students struggle to complete the research component, which is a requirement for registration with the Health Professions Council of South Africa (HPCSA).

Aim: To evaluate and uncover factors hindering research performance at a South African university, with a plan to implementing strategic and focused remedial action.

Methods: Post-graduate students in the School of Medicine were enrolled in a crosssectional descriptive study. Using self-administered questionnaires, students were requested to provide information on barriers hindering research performance. Raw data from questionnaires was captured and analysed using STATA software.

Results: A total 125 questionnaires were returned however some participants did not answer all the questions. The major reasons for non-performance were cited as; lack of prior research experience with only 14 per cent having had prior research exposure. Regarding association of research methodology (REME) course attendance with students starting research activities, 90 per cent of those that had attended the REME course, had started research activities at the time of this study. Research supervision was cited as inadequate by 48 per cent of respondents, while 61 per cent cited excessive workload as factor another factor hampering research course attendance and research participation. Most students indicated the need to have research taught and incorporated in the Masters curriculum, with time ring-fenced for research activities.

Conclusion: Prior research exposure and attendance of a research course were important factors influencing students' participation in research and should be encouraged. The institution should strive to improve supervisory and mentoring support as well as provide bio-statistics support. There is a need to ring-fence time specifically for research activities in order to counter 
the workload issue as a deterrent to research activities.

Keywords: research, supervision, education, training, university

\section{INTRODUCTION}

Research performance at institutions of higher education in South Africa is a historically complex one, with some institutions performing better than others. Institutions were previously categorised and funded according to racial divide, with formerly white universities wellresourced and well-funded whereas formerly black institutions were poorly funded and under resourced (Academy of Science of South Africa (ASSAf)) 2009). Sefako Makgatho Health Sciences University, which was formerly designated as a rural black university, finds itself in a situation where the institution has to catch up with well-resourced sister universities. Notably, a study done in the United States of America also cites similar challenges of lack of financial resources to attract faculty and offer student scholarships, in their historically black colleges and universities, coupled with competition from well-resourced institutions (HBCU) (Gasman and Commodore 2014).

Difficulties postgraduate students encounter during their training, specifically in research, is not unique to South Africa, but has been observed in other countries as well. A study conducted in India found out that there was a lack of transformation of knowledge into actual research due to time constraints and inadequate research curriculum (Giri, Bangal and Phalke 2014). Albertyn, Von Coller-Peter and Morrison (2016) indicated that sometimes students viewed research as a necessary evil towards obtaining higher degrees. Furthermore, inadequacies in research teaching are not unique to underdeveloped countries. Lemon (2013) writing in an editorial regarding research training laments that medical doctors were not being equipped with the necessary research skills to practice up to date evidence-based medicine. $\mathrm{He}$ further indicated that, in the United Kingdom, teaching on research techniques and skills of undergraduate students was lacking although statistics was adequately covered.

Scholarly teaching is said to be complex, encompassing various research contexts with processes that incorporate integrated research into teaching activities. This is achieved through use of inquiry and investigation, where students are taught research in a scholarly environment, in accordance with modern practices and knowledge (De Jongh, Frantz and Rhoda 2014). The complexity of research activities was considered by Albertyn et al. (2016) who suggested that such activities should incorporate research teaching and supervision. The same study also suggested that research education should not only be restricted to classrooms, but also be incorporated into programs that would give holistic student support (Albertyn et.al. 2016). Academic writing should be developed, to support academics in overcoming key barriers. 
These include not considering writing as a priority, and then consequently not publishing (Kapp, Albertyn and Frick 2011; Murray and Murray n.d.) although these same academics are expected to oversee research activities.

Research performance is also affected by factors such as lack of adequate preparation, social factors and negative attitudes towards research (Albertyn, Kapp and Bitzer 2009). Student preparedness affects student success in higher education, with better-prepared students achieving better outcomes than their counterparts (Roman, Titus and Dison 2016). Prior research exposure as a form of preparation was found to be a factor influencing success in postgraduate research. Individuals with prior undergraduate research experience tended to be more involved in post-graduate activities than their colleagues could (Sabzwari, Kauser and Khuwaja 2009; Segal et al. 1990). Poor numeracy skills also play a role, particularly in relation to planning, interpretation and understanding of the results. Social factors such as financial and family can cause students to experience distress as they progress in their post graduate career (Abiddin and Ismail 2011).

Generally, a number of postgraduate students perceive research as a daunting task due to challenges such as topic selection, literature reviews, research planning and designing and conducting the actual research (ASSAf 2009).

In the USA for example, it was established that students viewed research courses negatively, preferring structured courses, discussions and group activities, as they found these to be more enjoyable (Lei 2008). Furthermore, in Pakistan, Aslam found out that inappropriate research awareness and training were factors that contributed to poor research activity (Aslam et al. 2004). Other than these factors, culture, gender, race, age, marital status and background knowledge were also as identified as factors that confronted students in doing research projects (Maccio 2011). These findings highlight the complexity of postgraduate research training.

Furthermore, students support services such as supervision was another important factor that needed to be addressed. It was also argued that time constraints usually denied students the much-needed support, owing to the teachers' heavy clinical workloads. These contributed to inadequate students' supervisory support, and in turn affecting students' performance as there was limited student-supervisor relationship which is an important aspect for the success of such projects (Abdelhafez 2007). According to Bateman (2011), only 1 per cent of health-care professionals have doctoral qualifications and this becomes an issue to identify enough supervisors who can coach doctoral students during their research projects. This shortage leads to increases in the workloads of the few supervisors available, making their task difficult and tedious.

Similarly, Bateman (2011) observed that getting mentors became complicated when the 
available few supervisors had heavy clinical workload and shared their time between clinical practice and student supervision. This is the reason Bitzer and Albertyn (2011) suggested that in moments like these where limited supervisors become an issue an alternative model of supervision needs to be founded. They then recommended group supervision and team approaches, as more effective solutions compared to the traditional one-on-one supervision. This was bearing in mind the complexity of supervisory roles, and the fact that supervisors would need to adapt to new ways of student supervision.

It was also noted that the supervisory role changed depending on the academic tier of supervision, with Masters students requiring more support than their doctoral colleagues (Albertyn, Kapp and Bitzer 2009). This indicated that research supervision should be tailored to the academic level and needs of the students. In order for students to engage meaningfully with research activities, they need to be taught, guided and mentored. This requires assistance from supervisors, mentors and advisors (Bitzer and Albertyn 2011; Van Biljon and De Villiers 2013). Since the expectations from both the students and supervisors have to be met, studentsupervisor relationship therefore has to be mutually beneficial for the students to succeed in the research activities (Abdelhafez 2007).

In the South African context, training of medical post-graduate students encompasses coursework and a mini-dissertation to satisfy the university and HPCSA requirements for specialist registration (HPCSA 2010). The curriculum spans over four years for students in medical disciplines and five years for their surgical colleagues. Completion of a research thesis /mini-dissertation is compulsory for all medical specialists who entered the postgraduate training program after 2011 (HPCSA 2010). Prior to 2011, students who opted to do a fellowship with the College of Medicine of South Africa (CMSA) instead of a Masters degree did not have to fulfil the research university requirements to be registered with the HPCSA. As a result, there are a number of medical specialists involved in postgraduate training and supervision, who have not participated in, or had no exposure to research activities. Universities now face a situation where all postgraduate students have to fulfil the research requirement within the stipulated training period, yet some students may be supervised by lecturers who may not have done research themselves.

Students also face other complex challenges such as patient care workloads and teaching of undergraduate students, as they attempt to satisfy the prescribed coursework and research requirements. Since all these factors play an important role in the holistic student performance, it is important for students to be given a voice, as this will enable the institution to listen and understand the nature of the underlying issues hence institute focused programs that can address students concerns (Albertyn, Kapp and Bitzer 2009). 
Accordingly, this study aimed to investigate the factors affecting research performance among postgraduate students in the School of Medicine at Sefako Makgatho Health Sciences University (SMU) in South Africa. Although research has been conducted in various fields of postgraduate education and research in particular, none has been conducted in South Africa on challenges postgraduate medical students face in undertaking research in this specific institution. Awareness of these challenges would assist the university to focus attention on resolving these issues and thus improve research performance and outcomes.

\section{RESEARCH METHODS}

The study was conducted at Sefako Makgatho Health Sciences University (SMU) in South Africa. The study population consisted of medical postgraduate students registered at SMU. A stratified sample size (stratified for departments) of 125 Masters of Medicine students was recruited for this study although the target was 184 . A response rate of 65 per cent was expected although some participants did not answer all of the questions thus creating differing totals for different questions. Participants were also recruited from 17 of the 24 disciplines in the School of Medicine. This is because some departments did not return the questionnaires and the researcher was denied access to one department. The sample size was determined using the StatCalc module of the statistical package Epi-Info using the assumptions that population size of postgraduate students in the school of Medicine totalled 350. The level of significance of all tests was fixed at 5 per cent level, and therefore the proportion of attribute was fixed at 50 per cent level. The design effect was equal to 1. All students registered for a postgraduate Masters of Medicine degree from the second year onwards, including a few first-year students who had passed their primary examinations were eligible to participate in this study. The majority of the first-year students were excluded from the study as most of them do not commence research activities prior to passing the primary examination in their disciplines and are therefore unaware of the challenges.

Standard ethical procedures and guidelines as stipulated in the Helsinki Declaration were adhered to during the study. Ethics approval was obtained from the Research Ethics Committee at SMU (Ethics Ref No. SMUREC/M/261/2015). Permission was also obtained from the academic executives at Dr George Mukhari Academic hospital where these students are trained and employed. All participants took part in the study voluntarily. Responses obtained from participants were kept strictly confidential. An information sheet explaining the purpose of the study and a consent form were also distributed to the students.

Data was collected using a self-administered structured, pre-tested and validated questionnaire. The attitude questionnaire was based on a five tier Likert Scale ranging from strongly disagree to strongly agree. The questions relevant in this article covered the aspects 
presented in Table 1.

Table 1: Extract from the questionnaire relevant for this article

\begin{tabular}{|c|l|l|l|l|l|l|}
\hline & & $\begin{array}{c}\text { Strongly } \\
\text { disagree }\end{array}$ & Disagree & $\begin{array}{c}\text { Neither agree } \\
\text { nor disagree }\end{array}$ & Agree & $\begin{array}{c}\text { Strongly } \\
\text { agree }\end{array}$ \\
\hline 1 & I find research difficult & & & & & \\
\hline 2 & $\begin{array}{l}\text { In my department, there is } \\
\text { adequate supervision in } \\
\text { research }\end{array}$ & & & & & \\
\hline 3 & $\begin{array}{l}\text { The courses given at SMU } \\
\text { are adequate to equip } \\
\text { students to do research }\end{array}$ & & & & & \\
\hline 4 & $\begin{array}{l}\text { There is adequate time set } \\
\text { aside for students to conduct } \\
\text { research }\end{array}$ & & & & & \\
\hline 5 & $\begin{array}{l}\text { Research is important and } \\
\text { should be taught as a course }\end{array}$ & & & & & \\
\hline 6 & $\begin{array}{l}\text { Research should be } \\
\text { incorporated into the M Med } \\
\text { curriculum }\end{array}$ & & & & & \\
\hline
\end{tabular}

This questionnaire was re-designed and modified following Abdelhafez (2007) to accommodate for the current research question and the extract from the questionnaire is presented in Table 1. The completed questionnaires were, in most cases collected by the principal researcher. Data were collected, checked for accuracy, coded and entered into an Excel Spread-sheet and then exported to STATA version 13 for analysis. Information provided in the open-ended question was also coded and used in the analysis. Statistical procedures such as frequency tables, and summary statistics were presented. Research variables of interest are presented and discussed in Table 2 as follows.

Table 2: Description of study variables

\begin{tabular}{|c|c|}
\hline Variable & Description \\
\hline $\begin{array}{l}\text { Research } \\
\text { experience }\left(\mathrm{X}_{1}\right)\end{array}$ & $\begin{array}{l}\text { It is a measure of whether respondents/students had ever been trained in research methodology } \\
\text { course (REME) or a dissertation writing workshop. Respondents who had been trained in both } \\
\text { REME and a dissertation writing workshop were regarded to having had research experience, }\left(X_{1}\right. \\
=1 \text { ) and = } 0 \text { if otherwise. }\end{array}$ \\
\hline $\begin{array}{l}\text { Ethics protocol } \\
\text { approval }\left(\mathrm{X}_{2}\right)\end{array}$ & Average period (in months) within which research protocols are approved. \\
\hline $\begin{array}{l}\text { Student support } \\
\left(\mathrm{X}_{3}\right)\end{array}$ & $\begin{array}{l}\text { This variable provides an insight into the level of research supervision support received by } \\
\text { students. We used a dummy variable to proxy the level of support students receive, whereby } \mathrm{X}_{3}= \\
1 \text {, if student feels that s/he receives adequate research supervision and }=0 \text {, if otherwise. All } \\
\text { students who either agreed or strongly agreed that there was adequate supervision in research in } \\
\text { their department were categorised as those feeling that they received adequate research } \\
\text { supervision while those who disagreed or neither agreed nor disagreed felt that research } \\
\text { supervision was inadequate. }\end{array}$ \\
\hline Workload $\left(\mathrm{X}_{4}\right)$ & $\begin{array}{l}\text { In this context, workload refers to all scholarly activities, including research, patient care, } \\
\text { coursework, assignments/take-home as well as written examinations respondents undertake. } \\
\text { Students with a lot of activities tend to thinly allocate the limited time across activities that require } \\
\text { relatively urgent attention for them to pass, for instance examinations and assignments, thereby } \\
\text { jeopardising time allocated for research activities. A dummy variable }\left(X_{4}\right) \text { was used to ascertain } \\
\text { the number of students who felt like they had a lot of work to do (workload). All students who } \\
\text { indicated that they either strongly disagreed, disagreed or neutral (neither agree nor disagree) } \\
\text { were categorised as those who felt that the workload was too much }\left(X_{4}=1\right) \text {. Conversely, students } \\
\text { who either agreed or strongly agreed that had adequate time set aside to conduct research were } \\
\text { regarded as those who felt that the workload was not too much }\left(X_{4}=0\right) \text {. }\end{array}$ \\
\hline
\end{tabular}




\section{RESULTS}

\section{Summary statistics}

Although the study covered 125 students, in some instance responses were not given for some questions. Thus, the number of responses (sample size) varied from question to question. Overall, the estimated Cronbach Alpha coefficient was equal to $0.4964=49.64$ per cent, which is much smaller than 70 per cent, thus suggesting that although the measurements made during data collection were reliable, there was some degree of bias in the questionnaire design. Study participants were ethnically black (86\%), of African origin, with a male predominance of 62 per cent (Table 3). More than 50 per cent of the students were from the surgical discipline and about 50 per cent of the respondents were in either the $3^{\text {rd }}$ or $4^{\text {th }}$ year of study at SMU. Only 15.8 per cent of them were in the bracket of five to eight years of study. The mean age was estimated at 36 years, with a standard deviation (SD) of 6.07. The youngest student was 27 years while the oldest was 53 years old.

Table 3: Summary of characteristics of the study sample

\begin{tabular}{|c|c|c|}
\hline Characteristic & Size (n) & Percentage (\%) \\
\hline Ethnicity & & \\
\hline African & 107 & 76 \\
\hline Caucasian & 9 & 6 \\
\hline Asian & 7 & 1 \\
\hline Coloured & 1 & \\
\hline Gender & 78 & 62 \\
\hline Male & 47 & 38 \\
\hline Female & & 35 \\
\hline Year of Study & 42 & 49 \\
\hline $1-2$ & 59 & 13 \\
\hline $3-4$ & 15 & 3 \\
\hline $5-6$ & 4 & \\
\hline $7-8$ & & 26 \\
\hline Disciplines & 32 & 53 \\
\hline Medical & 66 & 21 \\
\hline Surgical & 27 & \\
\hline Imaging and other & & \\
\hline
\end{tabular}

Figure 1 shows the results captured from the questionnaire, indicating the students' perspectives. Some students felt that conducting research was difficult and that research supervision in their departments was inadequate. In addition, research was identified to be important, and it was argued that it should be taught as a course and incorporated in the M Med curriculum at the institution. Furthermore, it was emphasised that time allocated to research activities was inadequate. 


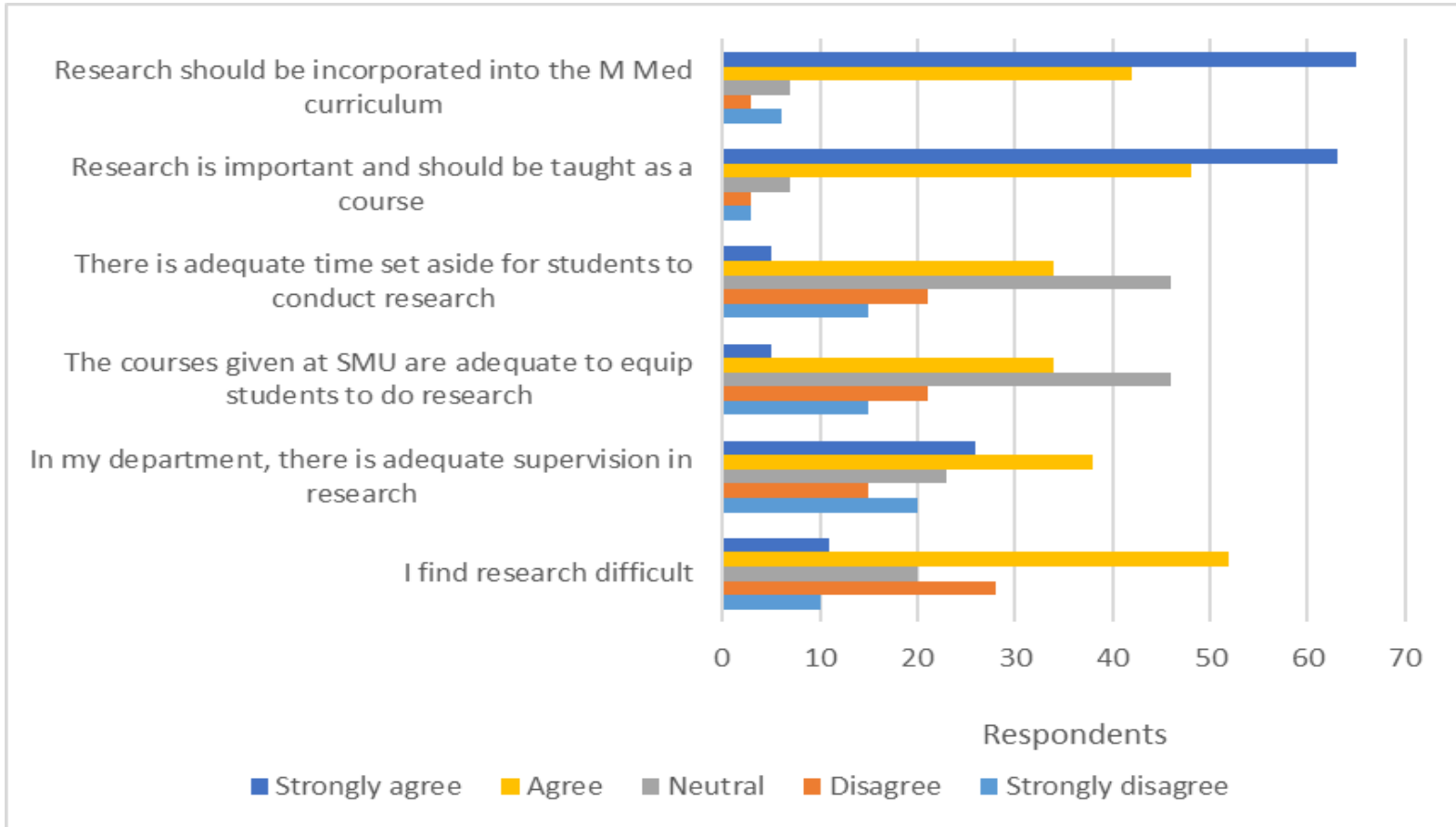

Figure 1: Graph showing selected responses to survey questions

A detailed discussion regarding prior research experience, attendance of research courses and training, ethics protocol approval, as well as student support in form of supervision and time allocated for research activities due to workload issues are discussed further in the subsequent paragraphs below.

\section{Research experience $\left(X_{1}\right)$}

Findings suggest that only 17 students (14\%) had research experience, measured as having been trained in both REME and dissertation writing workshop (Table 4).

Table 4: Research experience, by attendance of REME and dissertation writing workshop

\begin{tabular}{|c|c|c|c|}
\hline Description & Response & $\mathbf{n}$ & $\%$ \\
\hline \multirow{2}{*}{ Trained in both REME and dissertation workshop } & Yes & 17 & 14 \\
\hline & No & 104 & 86 \\
\hline \multirow{2}{*}{ Trained in dissertation writing workshop } & Yes & 38 & 32 \\
\hline & No & 82 & 68 \\
\hline \multirow{2}{*}{ Trained in research methodology (REME) course } & Yes & 79 & 63 \\
\hline & No & 46 & 37 \\
\hline
\end{tabular}

Thus, although a small proportion of the students (14\%) had been trained in both REME and dissertation writing workshop thereby implying that students had little research experience, other students had been trained in at least one of the two. For instance, 63 per cent of the students interviewed had been trained in research methodology course while 32 per cent had participated in a dissertation writing workshops only. 
As illustrated in Table 5, most students who had attended any one of the research training courses, had started conducting research projects at the time of the study.

Table 5: Students who started research as per research experience $\left(X_{1}\right)$ dimensions

\begin{tabular}{|c|c|c|c|}
\hline Description & Response & $\mathbf{n}$ & $\%$ \\
\hline \multirow{2}{*}{$\begin{array}{l}\text { Trained in both the REME course and dissertation workshop plus started } \\
\text { research }\end{array}$} & Yes & 17 & 89 \\
\hline & no & 2 & 11 \\
\hline \multirow{2}{*}{ Trained in dissertation writing workshop and started research } & Yes & 38 & 95 \\
\hline & no & 2 & 5 \\
\hline \multirow{2}{*}{ Trained in REME course and started research } & Yes & 65 & 90 \\
\hline & no & 7 & 10 \\
\hline
\end{tabular}

Regarding association of REME course attendance with students starting research activities. 90 per cent of those that had attended the REME course, had started research activities at the time of this study. On the other hand, of the 48 students who had not attended this course, only 50 per cent had started research activities. There was an overwhelming desire to have the course taught and incorporated in the curriculum although the numbers showed that the available courses were poorly attended.

\section{Ethics protocol approval $\left(\mathbf{X}_{2}\right)$}

Students argued that the delay to approve ethics protocols was a key deterring factor for them to embark on research. The time required to approve protocols ranged from 1 to 6 months but about 35 per cent of students' ethics protocols took more than 6 months to be approved as illustrated in Table 6.

Table 6: Time taken for protocol ethics approval

\begin{tabular}{|c|c|c|}
\hline Description & $\mathbf{n}$ & $\%$ \\
\hline $0-1$ month & 5 & 7 \\
\hline $1-3$ months & 23 & 32 \\
\hline $3-6$ months & 19 & 26 \\
\hline 6 months $<$ & 25 & 35 \\
\hline
\end{tabular}

\section{Student support $\left(X_{3}\right)$}

Fifty-two per cent (52\%) of the students felt that there were adequate student support services, particularly in form of research supervision. Thus, 56 per cent of those who mentioned that there was adequate research supervision were mainly in the surgical disciplines as compared to the 46 per cent from other disciplines. Fifty-four per cent of the students in the non-surgical disciplines felt that research supervision was not adequate as illustrated in table 7 
Table 7: Responses on adequacy of student supervision

\begin{tabular}{|l|c|c|c|c|c|}
\hline \multicolumn{1}{|c|}{ Description } & $\begin{array}{c}\text { Strongly } \\
\text { disagree }\end{array}$ & Disagree & $\begin{array}{c}\text { Neither agree } \\
\text { nor disagree }\end{array}$ & Agree & $\begin{array}{c}\text { Strongly } \\
\text { agree }\end{array}$ \\
\hline There is adequate student supervision & 20 & 15 & 23 & 38 & 26 \\
\hline Supervision is adequate & \multicolumn{3}{|c|}{58} & 64 \\
\hline Share (\%) & \multicolumn{3}{|c|}{47.5} & 52.5 \\
\hline
\end{tabular}

\section{Workload $\left(\mathrm{X}_{4}\right)$}

With regards to workload, 61 per cent indicated that there was not enough time allocated to research activities due to workload issues (Table 8).

Table 8: Responses on the availability of adequate time set aside for research, as a measure of workload

\begin{tabular}{|l|c|c|c|c|c|}
\hline \multicolumn{1}{|c|}{ Description } & $\begin{array}{c}\text { Strongly } \\
\text { disagree }\end{array}$ & Disagree & $\begin{array}{c}\text { Neither agree } \\
\text { nor disagree }\end{array}$ & Agree & $\begin{array}{c}\text { Strongly } \\
\text { agree }\end{array}$ \\
\hline $\begin{array}{l}\text { There is adequate time set aside for } \\
\text { students to conduct research }\end{array}$ & 15 & 21 & 46 & 34 & 5 \\
\hline Workload is much & \multicolumn{3}{|c|}{82} & 39 \\
\hline Share (\%) & \multicolumn{3}{|c|}{67.8} & 32.2 \\
\hline
\end{tabular}

Findings at program level (5- and 4-year program categories) revealed that 62 students from the 4 year programs and 33 students from 5 year programs did not have enough time allocated for research activities (Table 9).

Table 9: Time allocated for research activities by program

\begin{tabular}{|c|l|c|c|}
\hline \multicolumn{1}{|c|}{ Program } & Response & $\mathbf{n}$ & $\mathbf{\%}$ \\
\hline \multirow{2}{*}{ 5-year program } & Adequate & 8 & 6 \\
\hline \multirow{2}{*}{ 4-year program } & Inadequate & 33 & 27 \\
\cline { 2 - 4 } & Adequate & 20 & 16 \\
\cline { 2 - 4 } & Inadequate & 62 & 50 \\
\hline
\end{tabular}

This implies that students were overloaded with other activities, there by jeopardising the time that should have been devoted to research activities.

\section{DISCUSSION}

There are many challenges encountered by students in various institutions of higher learning with regard to research performance. Although these issues vary from place to place, there is a need for them to be addressed, in order to assist students complete their research activities in time. Postgraduate students are mature individuals who have to balance social activities, patient 
care, training and research during the postgraduate training period. The training period is limited and requires that students be given as much support as possible to enable them to complete their studies in time. The current study indicated that a good number of students found research activities daunting. This finding concurs with what is cited in the consensus report by the study panel appointed by the ASSAf (2009).

\section{Prior research training/exposure}

Having had prior research exposure was a major advantage in a sense that about 90 per cent of students (average) who had attended the research methodology course (REME) and dissertation workshop had started research activities at the time this study was conducted. However, most of the students surveyed, had no prior exposure to research activities during the undergraduate training and as a result, they needed to be taught research skills during postgraduate training. Studies have shown that prior research exposure can be an added advantage to students doing research (Maccio 2011). This finding explains sentiments by students expressing their need to have formal lectures in research and have it incorporated into the curriculum. The formal lectures would assist in focused research education. Our findings relate with results by Giri et al. (2014) who found out that 79.3 per cent of the students felt that research should be allocated time separately while planning postgraduate curricula, and 87.9 per cent indicated the need for guidance and supervision (Giri, Bangal and Phalke 2014).

Although there are some introductory initiatives offered at the university to assist students in preparation for research; for instance, REME and dissertation writing workshops, they are not compulsory. It is the prerogative of the heads of departments and students to ensure compliance. The REME course contributes to academic credits for the Masters course, and it is assumed that all students would attend this course prior to commencing research activities. In spite of this requirement, the results showed that only just over half of the participants $(50 \%)$ had attended the course and only a few of the students had attended the dissertation workshop courses offered at the institution. Of the students that had attended the REME course, many of them had gone on to participate in research activities, whereas only one third of the students had managed to start research activities without attending any research courses. Poor attendance of the research courses offered at the institution needs to be addressed, and some degree of monitoring needs to be put in place. There has to be a change in attitude where students should be encouraged to utilise available resources. This however does not negate the students concerns that the available courses are not adequate.

There was unanimous agreement by almost all respondents that bio-statistical knowledge was important in research, and yet statistical support was lacking at the institution. It would 
therefore be important for the institution to improve student support in form of statistics courses and on-site statisticians to be readily available to assist students during the designing, planning and reporting of research projects.

\section{Ethics protocol approval}

Delays in approval of protocols were cited as one of the challenges and sources of discouragement. Delays mainly arise from the fact that the supervisors may as well be overloaded with clinical work thereby jeopardising the time that should be accorded to the protocols given that they may not be a priority on their agendas. The institution needs to find ways of speeding up review and approval of protocols.

\section{Research supervision}

Only 50 per cent of students felt that there was inadequate research supervision in their departments, with some, indicating in the open answer question that some supervisors lacked supervisory skills. As a result, performing research activities was found to be daunting as they did not get adequate guidance. Training the supervisors would assist in solving this problem.

\section{Workload}

The workload was also cited as a contributory factor to non-performance of research, with the majority of students indicating that there was not enough time allocated for research activities away from the clinical working environment. This finding concurs with what (Abdelhafez 2007) found. The students therefore felt that a dedicated research block would assist them in focusing on their research projects. The students in the surgical disciplines were more affected by workload pressure compared to their colleagues in the non-surgical disciplines.

\section{LIMITATIONS}

Only 17 of the 24 disciplines participated in the study due to failure of completion of questionnaires and refusal of access to students in one discipline. This limited comparison and generalisability of the findings. A future in depth study would have to include all disciplines in the school and possibly extend this research to other universities.

This was an exploratory study and therefore, implementation of interventions should be considered for a focused group of students, and post intervention survey should be done to measure the impact of intervention as this would form a basis for future interventions. 


\section{CONCLUSION AND RECOMMENDATIONS}

The aim of this study was to identify factors hindering research performance among medical postgraduate students at SMU. Considering the above findings, the following recommendations are drawn, with a view to implement focused programs to assist students.

Research activities should be introduced earlier in the medical career and not at postgraduate level. Our results showed that research training needed to be improved, with 90 per cent of the responders in favour of dedicated teaching and allocation of time for research activities.

The age restriction criteria to access research funding and research opportunities should be removed to include advanced age (36 years and more) medical postgraduate students. The courses currently offered by the SMU appear to be adequate. However, a needs analysis should be conducted in order to introduce targeted courses. Most of the training would have to be done at institutions of learning since it was established that the majority of participants are above 36 years of age, indicating that these students would not fall into the category of young researchers. The advanced age is due to the lengthy training period for medical students ( 6 years) coupled with internship and community service. Unfortunately, the research training and funding programs in South Africa mainly target "young" researchers under the age of 35years (NRF 2005). This puts medical postgraduate students at a disadvantage as they are unable to access additional research training and funding opportunities prior to enrolling for the postgraduate training, and yet research training is not offered at the undergraduate level of training.

Student attendance of the available courses should be encouraged and measurable outcomes should be monitored. Improvement of supervisory and mentoring support by capacitating the supervisors needs urgent attention.

Additional assistance in form of statistical packages and analysists should be readily available on campus. This would further assist students in performing and completing research activities in time. Ring-fencing research time in study-blocks on a rotational basis with measurable outcomes would also assist students focus on research activities. There is a need to put in place adequate research structures. This will enable most students complete research activities timeously and also overcome the perceived daunting task of undertaking research.

Approval of protocols needs to be speeded up in order for students to get timeous feedback and effect the necessary changes for them to commence research activities within the stipulated time-frames. A deeper insight into drivers hindering timely approval of protocols should be done so as to design customised interventions to address this issue. 


\section{ACKNOWLEDGEMENTS}

Authors would like to thank the clinical heads of departments who allowed the research team access to the students and the students who participated in this study. Many thanks to Dr Ruth Albertyn for allowing us access to her scholarly work and for her valuable input into this manuscript. Prof Towobola for advice on improving the quality of the manuscript, Prof Schoeman for statistical support. Special thanks to Kisansa family for the quality time availed while undertaking this research.

\section{REFERENCES}

Abdelhafez, A. M. 2007. Postgraduate research students knowledge and attitudes towards good supervisory practice at the University of Exeter. Online submission.

Abiddin, N. Z. and A. Ismail. 2011. Effective supervisory approach in enhancing postgraduate research studies. International Journal of Humanities and Social Science 1(2): 206-217.

Academy of Science of South Africa. 2009. Consensus Report on Revitalising Clinical Research in South Africa. A Study on Clinical Research and Related Training in South Africa. Report of Academy of Science of South Africa. http://www.assaf.co.za/wp-content/uploads/2009/09/ ASSAf-Clinical-Report-2009.pdf

Albertyn, R. M., C. A. Kapp and E. M. Bitzer. 2009. Profiling exiting postgraduate students performance and experiences. South African Journal of Higher Education 22(4): 749-72. https://doi.org/ 10.4314/sajhe.v22i4.25814.

Albertyn, R., S. Von Coller-Peter and J. Morrison. 2016. Aligning student and supervisor perspectives of research challenges. In Postgraduate supervision: Future foci for the knowledge society, ed. M. Fourie-Malherbe, R. Albertyn, C. Aitchison and E. Bitzer, 171-187. Stellenbosch: SUN PRESS. doi:10.18820/9781928357223/10.

Aslam, F., M. A. Qayyum, H. Mahmud, R. Qasim and I. U. Haque. 2004. Attitudes and practices of postgraduate medical trainees towards research - a snapshot from Faisalabad. JPMA. The Journal of the Pakistan Medical Association 54(10): 534-536.

Bateman, C. 2011. SA clinical research output in crisis. South African Medical Journal 101(9): 61416.

Bitzer, E. M. and R. M. Albertyn. 2011. Alternative approaches to postgraduate supervision: A planning tool to facilitate supervisory processes. South African Journal of Higher Education 25(5): 87488.

De Jongh, J., J. Frantz and A. Rhoda. 2014. Integrating research into teaching: Needs assessment for staff development. African Journal of Health Professions Education 6(2): 124-128. https://doi. org/10.7196/ajhpe.211

Gasman, M. and F. Commodore. 2014. The state of research on historically Black colleges and universities. Journal for Multicultural Education 8.2(2014): 89-111. https://doi.org/10.1108/ JME-01-2014-0004

Giri, P. A., V. B. Bangal and D. B. Phalke. 2014. Knowledge, attitude and practices towards medical research amongst the postgraduate students of Pravara Institute of Medical Sciences University of Central India. Journal of Family Medicine and Primary Care 3(1): 22. https://doi.org/ $10.4103 / 2249-4863.130263$

HPCSA see Health Professions Council of South Africa.

Health Professions Council of South Africa. 2010. PETM - New requirements for the registration of specialists in South Africa - 18 Nov 2009 ii-Edited. HPCSA, Pretoria.

Kapp, C. A., R. M. Albertyn and B. L. Frick. 2011. Writing for publication: An intervention to overcome 
barriers to scholarly writing. South African Journal of Higher Education 25(4): 741-759.

Lei, S. A. 2008. Factors changing attitudes of graduate school students toward an introductory research methodology course. Education 128(4): 667-85. http://search.ebscohost.com/login.aspx?direct= true $\& \mathrm{db}=$ fgh $\& \mathrm{AN}=32709000 \&$ site $=$ ehost-live

Lemon, T. I. 2013. Lack of research skills teaching not just an African education issue. African Journal of Health Professions Education 5(2): 100.

Maccio, E. M.. 2011. Graduate social work students attitudes toward service-learning. Journal of Teaching in Social Work 31(2): 163-77. https://doi.org/10.1080/08841233.2011.560539

Murray, R. and S. M. Murray. n.d. "Handbook of academic writing: A fresh approach." www.openup.co.ukm (Accessed 25 October 2016).

National Research Fund. 2014. Definition of rating categories. https://www.nrf.ac.za/sites/default/ files/documents/Definition\%20of\%20rating\%20categories.pdf

NRF see National Research Fund.

Roman, N. V., S. Titus and A. Dison. 2016. Relationship between student preparedness, learning experiences and agency: Perspectives from a South African university. African Journal of Health Professions Education 8(1): 30. https://doi.org/10.7196/AJHPE.2016.v8i1.490

Sabzwari, S., S. Kauser and A. K. Khuwaja. 2009. Experiences, attitudes and barriers towards research amongst junior faculty of Pakistani Medical Universities. BMC Medical Education 9: 68. https://doi.org/10.1186/1472-6920-9-68

Segal, S., T. Lloyd, P. S. Houts, P. L. Stillman and R. L. Jungas. 1990. The association between students' research involvement in medical school and their postgraduate medical activities. Academic Medicine: Journal of the Association of American Medical Colleges 65(8): 530-533. https://doi.org/10.1097/00001888-199008000-00010

Van Biljon, J. A. and M. R. De Villiers. 2013. Multiplicity in supervision models: The supervisors' perspective. South African Journal of Higher Education 27(6): 1443-1463. 